\title{
DEVELOPMENT AND VALIDATION OF BIOANALYTICAL HPLC METHOD FOR SIMULTANEOUS ESTIMATION OF CILNIDIPINE AND NEBIVOLOL IN HUMAN PLASMA
}

\author{
ARUNA G. ${ }^{*}$, BHARATHI K. ${ }^{2}$, KVSRG PRASAD ${ }^{2}$ \\ ${ }^{1}$ Department of Quality Assurance, Krishna Teja Pharmacy College, Tirupati, ${ }^{2}$ Institute of Pharmaceutical Technology, Sri Padmavati \\ Mahila Visvavidyalayam (Women's University), Tirupati, Andhra Pradesh, India
}

Email: garuna.mpharm@gmail.com

Received: 25 May 2017 Revised and Accepted: 31 Aug 2017

\begin{abstract}
Objective: To develop and validate a modified isocratic reversed-phase high performance liquid chromatographic (RP-HPLC) method for determination of cilnidipine and nebivolol in human plasma to be used for pharmacokinetic studies.

Methods: The drug was extracted from plasma samples by direct protein precipitation technique using acetonitrile. Amlodipine was used as internal standard (IS). Samples were analyzed on BDS C 18 column $(250 \times 4.6 \mathrm{~mm}, 5 \mu \mathrm{m})$, applying ortho phosphoric acid (0.1\%): Acetonitrile, at a ratio of $45: 55 \mathrm{v} / \mathrm{v}$ in isocratic mode as a mobile phase at a flow rate of $1 \mathrm{ml} / \mathrm{min}$ to attain adequate resolution. Separations were performed at room temperature and monitored at a wavelength of $260 \mathrm{~nm}$ after injection of $50 \mu \mathrm{l}$ samples into the HPLC system. The analytical method was validated according to FDA bioanalytical method validation guidance. The method was applied for pharmacokinetic study of cilnidipine and nebivolol tablets$10 \mathrm{mg}$ and $5 \mathrm{mg}$ were administered as a single dose to 6 healthy male rabbits under fasting condition. Twelve blood samples were withdrawn from each rabbit over $24 \mathrm{~h}$ periods. From the plasma concentration-time data of each individual, the pharmacokinetic parameters; Cmax, Tmax, AUC0-t and AUC $0-\infty$ were calculated.
\end{abstract}

Results: A peak area was obtained for cilnidipine and nebivolol at 3.943 and 4.719 min retention time respectively. Linearity was established at a concentration range of $0.20-20 \mu \mathrm{g} / \mathrm{ml}\left(\mathrm{r}^{2}=0.999, \mathrm{n}=8\right)$ for cilnidipine and $0.02-2 \mu \mathrm{g} / \mathrm{ml}\left(\mathrm{r}^{2}=0.999, \mathrm{n}=8\right)$ for nebivolol. The lower limit of quantitation (LLOQ) was identifiable and reproducible at $0.2 \mu \mathrm{g} / \mathrm{ml}$ for cilnidipine and $0.02 \mu \mathrm{g} / \mathrm{ml}$ for nebivolol. The coefficients of variation (\%cv) of the intra-day and inter-day precision of cilnidipine at 600,1000 and $1600 \mathrm{ng} / \mathrm{ml}$ levels were found to be $6.90 \%, 6.19 \%, 5.22 \%$; and $7.74 \%, 6.54 \%$, 5.77\%, respectively, which are lower than the accepted criteria limits (15-20 \%). The mean recovery (\%) cilnidipine at 600,1000 , and $1600 \mathrm{ng} / \mathrm{ml}$ was found to be $101.03 \%$, $99.27 \%$ and $104.87 \%$, and for nebivolol 60,100 , and $160 \mathrm{ng} / \mathrm{ml}$ was found to be $106.13 \%, 107.03 \%$ and $98.06 \%$ respectively. Stability at different

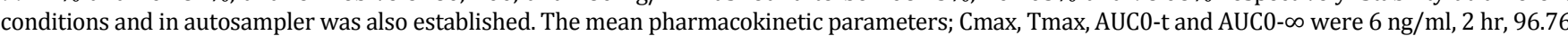
$\mathrm{mg} . \mathrm{hr} / \mathrm{ml}, 63.45 \mathrm{mg}$. hr/ml for cilnidipine and 5.8ng/ml, $2 \mathrm{hr}, 74.78 \mathrm{mg} . \mathrm{hr} / \mathrm{ml}, 100.25 \mathrm{mg} . \mathrm{hr} / \mathrm{ml}$ for nebivolol respectively.

Conclusion: The present analytical method was found to be specific, sensitive, accurate and precise for quantification of cilnidipine and nebivolol in human plasma. It can be successively applied for pharmacokinetics, bioavailability and bioequivalence studies.

Keywords: Cilnidipine, Nebivolol, HPLC, Human plasma, Pharmacokinetics

(C) 2017 The Authors. Published by Innovare Academic Sciences Pvt Ltd. This is an open access article under the CC BY license (http://creativecommons.org/licenses/by/4.0/) DOI: http://dx.doi.org/10.22159/ijpps.2017v9i10.20237

\section{INTRODUCTION}

Cilnidipine 1,4-dihydro-2,6-dimethyl-4-(3-nitrophenyl)-3,5-pyridinecarboxylic acid 2-methoxyethyl(2e)-3-phenyl-propenyl ester (fig. 1)is a novel and unique dihydropyridine calcium channel blocker that possesses a slow-onset, long-lasting vasodilating effect. Cilnidipine is used in the treatment of hypertension. Cilnidipine shows first pass mechanism. Cilnidipine is used in combination with others drugs like telmisartan, olmesartan. Cilnidipine and its formulations are not official in any pharmacopoeias [2]. Nebivolol hydrochloride is a $\beta 1$ receptor blocker. It is chemically (1rs, 1 'rs)1,1'-[(2rs, 2'sr)-bis (6-flurochroman-2-yl)]-2, 2'-iminodiethanol hydrochlo-ride (fig. 2). Nebivolol and cilnidipine are used alone in treatment of hypertension but when they are given in combination synergistic action obtained and hence dose is reduced.<smiles>COCCOC(=O)C1=C(C)NC(C)=C(C(=O)OC/C=C/c2ccccc2)C1c1cccc([N+](=O)[O-])c1</smiles>

Fig. 1: It shows chemical structure of cilnidipine<smiles>OC(CNCC(O)C1CCc2cc(F)ccc2O1)C1CCc2cc(F)ccc2O1</smiles>

Fig. 2: It shows chemical structure of nebivolol

To date several methods have been developed for the quantification of cilnidipine and nebivolol either alone or in combination with other drugs in different matrices [1-3]. HPTLC method reported for determination of nebivolol hydrochloride and cilnidipine in combined tablet dosage form [4]. The simultaneous quantification of cilnidipine combinations with olmesartan medoxomil, chlorthalidone, and valsartan in oral formulations were also reported [5-8]. Nevertheless, there is still an increasing interest for development of more specific, accurate, precise and rapid method for determination of cilnidipine and nebivolol especially in human plasma. The aim of this study was to develop and validate HPLC analytical method for determination of cilnidipine [9] and nebivolol in human plasma in order to be utilized for studying the pharmacokinetics of cilnidipine and nebivolol after a single oral dose of LNBETA tablets $10 \mathrm{mg}$ and $5 \mathrm{mg}$. 


\section{MATERIALS AND METHODS}

\section{Materials and reagents}

Waters HPLC equipped with Inertsil ODS $\mathrm{C}_{18}(250 \times 4.6 \times 5 \mu)$, column, solvents and buffers of HPLC grade purchased from Merck Ltd. API were procured as gift samples from Spectrum labs, Hyderabad and formulation LNBETA was purchased from local market, Hyderabad.

\section{Instruments}

Waters 2695 alliance HPLC system, Waters 2996 PDA detector. Empower-2 software (USA). Stuart scientific vortex shaker (England).

\section{Preparation of standard solutions}

Stock solution of cilnidipine $(10 \mathrm{mg} / \mathrm{ml})$ and nebivolol $(1 \mathrm{mg} / \mathrm{ml})$ was prepared in diluent (water: acetonitrile 50:50) using cilnidipine and nebivolol standard powders. The internal standard stock solution of amlodipine $(46 \mu \mathrm{g} / \mathrm{ml})$ was prepared in diluent using amlodipine standard powder. Working standard solutions of cilnidipine, nebivolol and amlodipine were prepared by dilution of their respective stock solution with a mixture of acetonitrile: water (50:50) to produce a final concentration of $10000 \mu \mathrm{g} / \mathrm{ml}$ and 1000 $\mu \mathrm{g} / \mathrm{ml}$ respectively.

\section{Standard calibration curve preparation}

Standard solutions of cilnidipine and nebivolol were prepared by serial dilution of working solution $(100 \mu \mathrm{g} / \mathrm{ml})$ with a mixture of acetonitrile: water (50:50) to attain a concentration of 46, 92, 138, $1150,1725,2300,3680$ and $4600 \mu \mathrm{g} / \mathrm{ml}$ for cilnidipine and 4.2, 10.08, $13,115,170,230,360$ and $450 \mu \mathrm{g} / \mathrm{ml}$ for nebivolol Amlodipine was used as internal standard which has been taken at a concentration of $46 \mu \mathrm{g} / \mathrm{ml}$ in each level. All solutions were prepared daily.

\section{Plasma sample preparation for calibration curve}

Human blood samples were transferred to heparinized tubes and then centrifuged at 4000rpm for $10 \mathrm{~min}$. The Plasma was separated by polypropylene disposable tips and stored at $-20^{\circ} \mathrm{C} \pm 2$ in the deep freezer until analysis.

The calibration curve of cilnidipine and nebivolol in plasma was constructed by spiking $900 \mu \mathrm{l}$ of plasma samples (which was first thawed at room temperature) with $100 \mu \mathrm{l}$ of the previously prepared standard solutions $(0.5,1.0,2.0,5.0,10.0$ and $15.0 \mu \mathrm{g} / \mathrm{ml}$, keeping internal standard amlodipine at a concentration of $10 \mu \mathrm{g} / \mathrm{ml}$ in each one). Accordingly, the plasma samples contain a final concentration of cilnidipine and nebivolol equivalent to 46, 92, 138, $1150,1725,2300,3680$ and $4600 \mu \mathrm{g} / \mathrm{ml}$ for cilnidipine and 4.2 , $10.08,13,115,170,230,360$, and $450 \mu \mathrm{g} / \mathrm{ml}$, for nebivolol respectively. Amlodipine was used as internal standard which has been taken at a concentration of $460 \mathrm{ng} / \mathrm{ml}$ in each. While blank plasma samples were spiked with $100 \mu \mathrm{l}$ of a mixture of acetonitrile: water (1:1). The samples were vortex to mix for 30 seconds to be applied to the extraction and analytical procedure.

\section{Quality control (QC) samples preparation}

Standard solutions of cilnidipine and nebivolol were prepared by serial dilution of working solution $(100 \mu \mathrm{g} / \mathrm{ml})$ with mixture of acetonitrile: water (50:50) to attain a concentration of $0.600,10.00$ and $16.00 \mu \mathrm{g} / \mathrm{ml}$ for cilnidipine and $0.060,1.000$ and $1.600 \mu \mathrm{g} / \mathrm{ml}$ for nebivolol QC samples preparation, keeping amlodipine internal standard at a concentration of $4.6 \mu \mathrm{g} / \mathrm{ml}$ in each. All solutions were prepared daily. Quality Control plasma samples were prepared by spiking $900 \mu \mathrm{l}$ of plasma samples (which was thawed at room temperature) with $100 \mu \mathrm{l}$ of the freshly prepared standard solutions $(0.60,10.0$ and $16.00 \mu \mathrm{g} / \mathrm{ml}$ of cilnidipine and $0.060,1.000$ and $1.600 \mu \mathrm{g} / \mathrm{ml}$ of nebivolol; with $4.6 \mu \mathrm{g} / \mathrm{ml}$ of amlodipine). Accordingly plasma samples contain a final concentration of cilnidipine and nebivolol equivalent to $600,1000,1600 \mathrm{ng} / \mathrm{ml}$ and $60,100,160 \mathrm{ng} / \mathrm{ml}$ respectively and $460 \mathrm{ng} / \mathrm{ml}$ of amlodipine as internal standard.

\section{Sample preparation for HPLC injection}

Drug was extracted from plasma samples using direct protein precipitation technique. $2 \mathrm{ml}$ of acetonitrile: water (50:50) was added to $250 \mu \mathrm{l}$ of plasma, $50 \mu \mathrm{l}$ of internal standard, $10 \mu \mathrm{l}$ of cilnidipine and $10 \mu \mathrm{l}$ of nebivolol spiked plasma samples. The samples were shaken and then centrifuged at $3200 \mathrm{rpm}$ for $20 \mathrm{~min}$. Finally $50 \mu \mathrm{l}$ of the clear supernatant were injected into the HPLC column.

\section{Chromatographic conditions}

The different HPLC experimental parameters were optimized. The optimized chromatographic conditions were column: BDS C18 column $(250 \times 4.6 \mathrm{~mm}, 5 \mu \mathrm{m})$, mobile phase: ortho phosphoric acid $(0.1 \%)$ buffer: acetonitrile $(45: 55, \mathrm{v} / \mathrm{v})$, detection: UV detector set at a wavelength $\lambda_{\max }$ of $260 \mathrm{~nm}$, flow rate: $1.0 \mathrm{ml} / \mathrm{min}$, injection volume: $50 \mu$ l, auto sampler temperature: ambient.

The mobile phase was always degassed and clarified by filtration through porous membranes with $0.45 \mu \mathrm{m}$ pore size. A mobile phase degasser was connected on line during the analysis runtime, and then pumped at a flow rate of $1 \mathrm{ml} / \mathrm{min}$, in isocratic mode on the column. The sample $(50 \mu \mathrm{l})$ was injected into HPLC system and the data was acquired employing Empower-2 software.

\section{Method validation}

The analytical method was validated according to ICH guidelines [15-17] with respect to the following parameters:

\section{Calibration and linearity}

The linearity of the method was established from the standard calibration curve constructed at several concentration levels of 0.2 $20 \mu \mathrm{g} / \mathrm{ml}$ and 0.02 to $2 \mu \mathrm{g} / \mathrm{ml}$ for cilnidipine and nebivolol respectively. Triplicate $50 \mu \mathrm{l}$ injections were made for each working standard solution. The peak area for each concentration was recorded and then plotted against the corresponding concentration to obtain the calibration graph. In addition, a blank and a zero sample were prepared to confirm the absence of interferences.

\section{Selectivity/specificity}

The Selectivity/specificity was evaluated by extracting different blank plasma samples. The absence of interfering peaks at the same retention time of analytes or internal standard (Amlodipine) was considered as evidence for selectivity/specificity

\section{Accuracy and precision \\ Intra-day accuracy and precision}

The intra-day precision and accuracy of the assay were measured by analyzing five spiked samples of cilnidipine and nebivolol at three different concentrations $(600,1000$ and $1600 \mathrm{ng} / \mathrm{ml}$ and 60,100 and $160 \mathrm{ng} / \mathrm{ml})$; the concentrations were calculated by using the regression equation of the calibration curve. The deviation of the mean from the true value serves as the measure of accuracy. The precision and accuracy deviation values should be less than $15 \%$ of the actual values except at lower limit of quantitation (LLOQ) where it shouldn't deviate $>20 \%$. The statistical evaluation includes mean, standard deviation (SD), coefficient of variation (\%CV) and accuracy.

\section{Inter-day accuracy and precision}

The inter-day precision were done at three different concentrations $(600,1000$ and $1600 \mathrm{ng} / \mathrm{ml}$ and $60,100,160 \mathrm{ng} / \mathrm{ml})$ over three days, the concentrations were measured by analyzing samples of five determinations from each concentration per day and were calculated applying the regression equation of the calibration curve. The statistical evaluation includes mean, SD, \% CV and accuracy.

\section{Accuracy and precision for quality control (QC) samples}

The accuracy and precision for QC samples were demonstrated by analyzing over two days duplicates of QC sample at three concentration levels representing the entire range of the standard calibration curve. The low QC samples $(600 \mathrm{ng} / \mathrm{ml}, 60 \mathrm{ng} / \mathrm{ml})$ were designed to be three times the LLOQ $(200 \mathrm{ng} / \mathrm{ml}, 20 \mathrm{ng} / \mathrm{ml})$, while the mid QC samples were taken at the center $(1000 \mathrm{ng} / \mathrm{ml}, 100 \mathrm{ng} / \mathrm{ml})$ and the high QC samples were taken near the upper limit of quantitation (ULOQ) which is $(1600 \mathrm{ng} / \mathrm{ml}, 160 \mathrm{ng} / \mathrm{ml})$. 


\section{Recovery}

It can be calculated by comparison of the analyte response after sample workup with the response of a solution containing the analyte at the theoretical maximum concentration.

The absolute recovery was calculated for cilnidipine, nebivolol and internal standard by comparing peak areas of the extracted samples with the un-extracted pure authentic standard solutions peak areas The relative recovery was determined for cilnidipine and nebivolol by comparing the calculated concentrations of extracted samples to their respective nominal values. Both absolute and relative recoveries of cilnidipine and nebivolol were measured at three concentration levels $(600,1000$, $1600 \mathrm{ng} / \mathrm{ml}$ and $60,100,160 \mathrm{ng} / \mathrm{ml}$ ).

\section{Sensitivity}

The lowest concentration in the calibration curve was considered as the LLOQ and should meet the following criteria; LLOQ response is five times the response of the blank, LLOQ response is identifiable, discrete and reproducible with precision of $20 \%$ and accuracy of $80-120 \%$.

The peak was identifiable, precise and accurate at this concentration. The LLOQ of cilnidipine and nebivolol in plasma was considered to be $200 \mathrm{ng} / \mathrm{ml}$ and $20 \mathrm{ng} / \mathrm{ml}$.

\section{Stability studies}

The stability of the cilnidipine and nebivolol in solutions and plasma samples was also evaluated during method validation. Cilnidipine and nebivolol stability was evaluated using two concentration levels (low and high quality control, corresponding to $600,1600 \mathrm{ng} / \mathrm{ml}$ and $60,160 \mathrm{ng} / \mathrm{ml}$ respectively). The stability of cilnidipine and nebivolol was also evaluated in post extracted samples kept in the auto sampler at $10{ }^{\circ} \mathrm{C}$ for $60 \mathrm{~h}$, as well as in plasma samples kept at freezer and after being stressed to 3 freeze-thawing cycles $(24 \mathrm{~h}$ each cycle). All samples described above were compared to freshly prepared cilnidipine and nebivolol samples at the same concentration level.

\section{Pharmacokinetic study in rabbits}

The method described above was applied to quantify the plasma concentration of cilnidipine and nebivolol in a single-dose pharma-cokinetic study [11-14] conducted on six white male albino rabbits. The protocol was approved by the institutional ethical committee at the Krishna teja pharmacy college, Tirupati, India and approval number was KTPC/IAEC/Ph. D/2015/I. The experiments were conducted as per CPCSEA guidelines. The rabbits weighing $2.5 \pm 0.3 \mathrm{~kg}$ were housed with free access to food and water, except for the final $12 \mathrm{~h}$ before experimentation. The rabbits were divided into 2 groups of 6 rabbits each with cross over technique $(n=6)$. All rabbits were fasted overnight, access to water during the experiment and the animals were fed $24 \mathrm{~h}$ after the oral dose. One group of animals received a single dose of pure drugs, formulated as a suspension containing sodium carboxy methyl cellulose. The second group was administered a solution containing marketed formulation at the same dose. $2.5 \mathrm{ml}$ of blood samples were collected from the marginal ear vein at $0,0.25,0.5$, $1,2,3,4,6,9,12$ and $24 \mathrm{hr}$ time points into heparinized collection tubes. The blood was immediately centrifuged for $10 \mathrm{~min}$ at cooling temperature. The supernatant plasma layer was separated and stored at $-20{ }^{\circ} \mathrm{C}$ until analyzed. The plasma samples were analyzed for cilnidipine and nebivolol concentrations as described above. The total area under the observed plasma concentrationtime curve (AUC) was calculated using the linear trapezoidal rule. The first order elimination rate constant $\left(\mathrm{K}_{\mathrm{e}}\right)$ was estimated by the least square regression of the points describing the terminal log-linear decaying phase. $t_{1 / 2}$ was derived from $K_{e}\left(t_{1 / 2}{ }_{1 / 4} \ln \right.$ $\left.2 / \mathrm{K}_{\mathrm{e}}\right)$. The absorption rate constant $\left(\mathrm{K}_{\mathrm{a}}\right)$ was determined by residual method. The maximum observed cilnidipine and nebivolol concentration $\left(c_{\max }\right)$ and the time at which $c_{\max }$ was observed $\left(t_{\max }\right)$ were reported directly from the profile.

\section{RESULTS AND DISCUSSION}

\section{Linearity}

The linearity of the method was evaluated from the calibration curve of spiked plasma samples at several concentration levels of cilnidipine and nebivolol (constructed for six consecutive days). The mean area (ratio of peak area of the drug to the peak area of the internal standard) yielded a linear correlation over a concentration range of $0.2 \mu \mathrm{g} / \mathrm{ml}$ to $20 \mu \mathrm{g} / \mathrm{ml}$ and $0.02 \mu \mathrm{g} / \mathrm{ml}$ to $2 \mu \mathrm{g} / \mathrm{ml}$ respectively. The method exhibited excellent linearity for this range. A typical calibration curve of spiked plasma samples with the regression equation and their respective correlation coefficient $\left(\mathrm{r}^{2}\right)$ of cilnidipine and nebivolol were shown in (fig. 3 and fig. 4). The average correlation coeffient was found to be 0.999 for both drugs with goodness of fit.

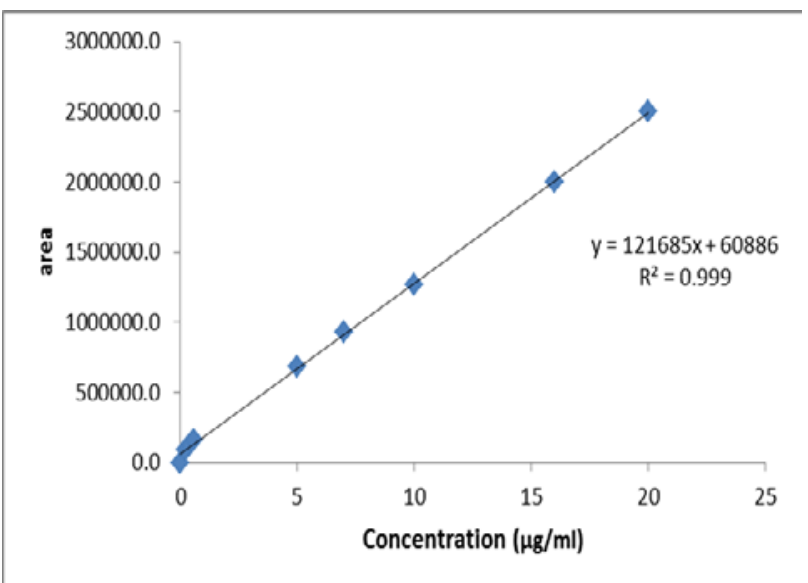

Fig. 3: It shows calibration curve of cilnidipine with amlodipine as internal standard in human plasma

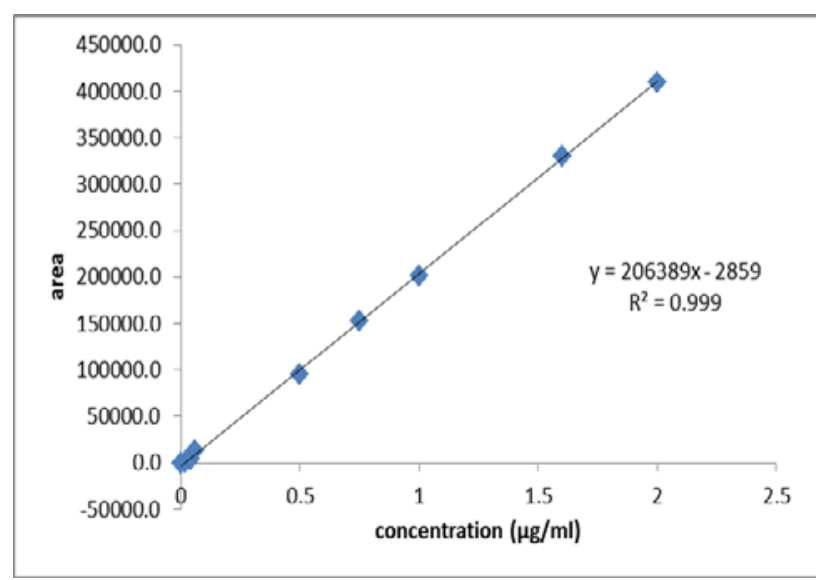

Fig. 4: It shows calibration curve of nebivolol with amlodipine as internal standard in human plasma

\section{Specificity/selectivity}

Representative chromatogram of blank plasma confirmed there is no significant interference from the endogenous component as shown in (fig. 5). Chromatograms of spiked plasma samples of cilnidipine and nebivolol at concentration of $200 \mathrm{ng} / \mathrm{ml}$ and $20 \mathrm{ng} / \mathrm{ml}$ respectively with the internal standard amlodipine at a constant concentration (460ng/ml) confirming that cilnidipine, nebivolol and amlodipine were well resolved and completely separated at retention times of $3.976,4.835$ and $5.794 \mathrm{~min}$, respectively as shown in (fig. 6, 7). 


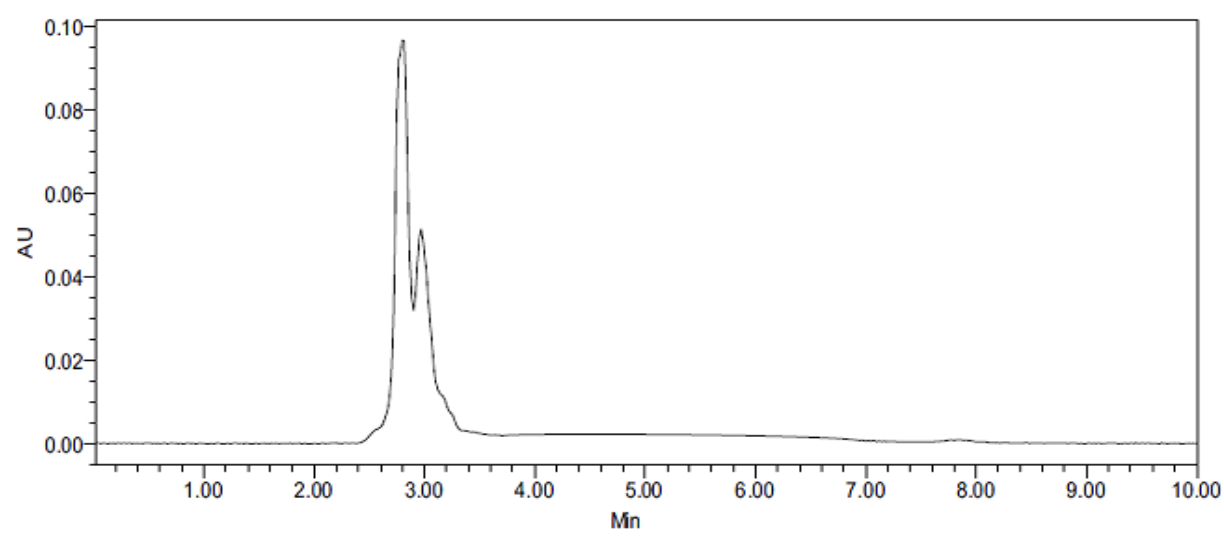

Fig. 5: It shows HPLC chromatogram of a blank human plasma sample

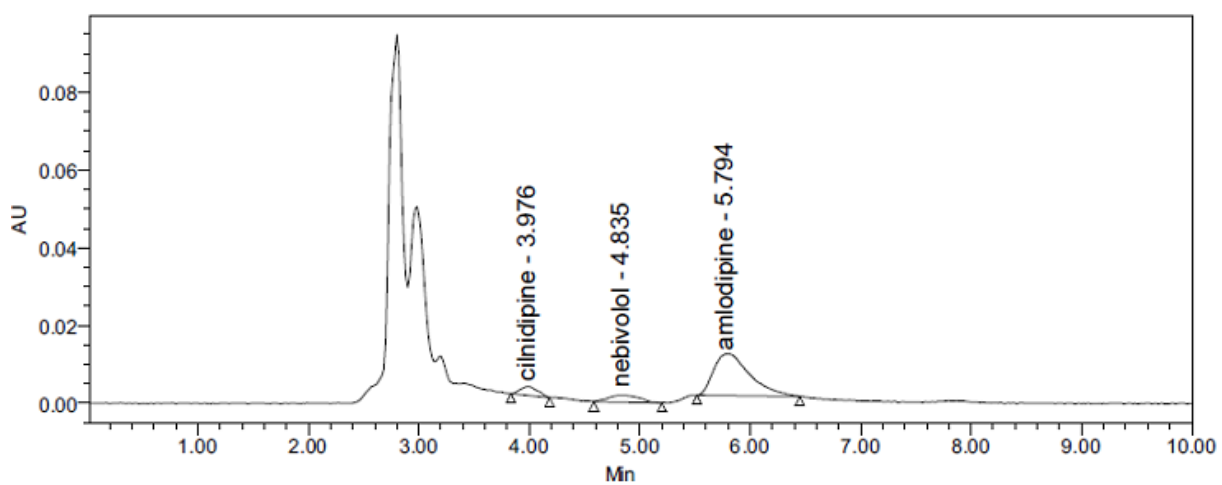

Fig. 6: It shows HPLC chromatogram representing complete resolution of the internal standard (IS) amlodipine peak from cilnidipine $(200 \mathrm{ng} / \mathrm{ml})$ and nebivolol $(20 \mathrm{ng} / \mathrm{ml})$ peak at a retention time $5.794,3.976$ and $4.835 \mathrm{~min}$, respectively

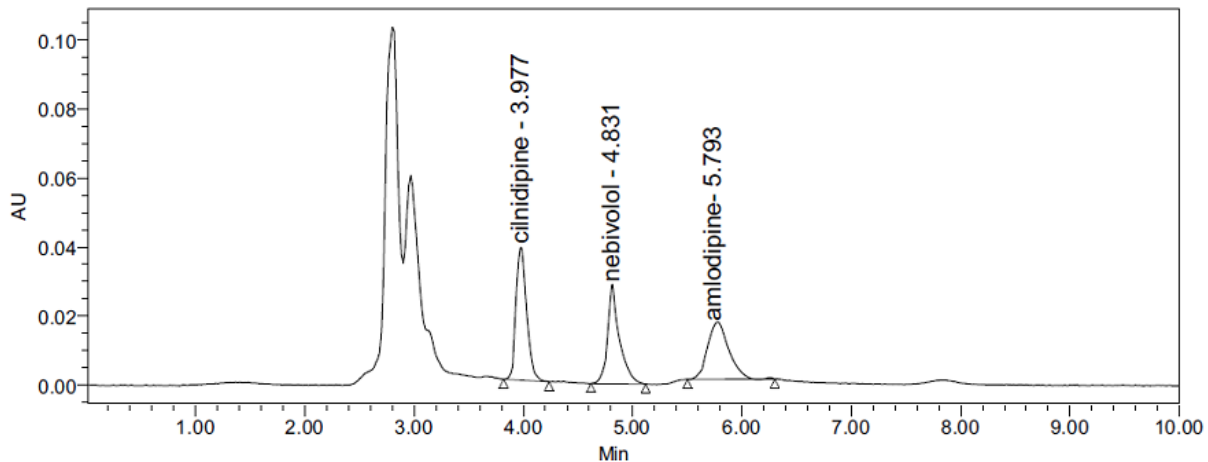

Fig. 7: It shows HPLC chromatogram representing complete resolution of the internal standard (IS) amlodipine peak (460ng/ml) from cilnidipine peak $(1600 \mathrm{ng} / \mathrm{ml})$ and Nebivolol $(160 \mathrm{ng} / \mathrm{ml})$ at a retention time 3.9 and $4.8 \mathrm{~min}$, respectively

\section{Accuracy and precision}

Intra-day accuracy and precision

Intra-day accuracy of the method for cilnidipine and nebivolol were ranged from $99.27 \%$ to $104.87 \%$ and $98.06 \%$ to $107.03 \%$ respectively. While the intra-day precision ranged from $5.22 \%$ to $6.90 \%$ at the concentrations of 600,1000 and $1600 \mathrm{ng} / \mathrm{ml}$ for cilinidipine and $7.24 \%$ to $11.49 \%$ at the concentration of $60,100,160 \mathrm{ng} / \mathrm{ml}$ for nebivolol.

The results were presented in (table 1).

Table 1: It shows intra-day precision and accuracy for cilnidipine and nebivolol in spiked human plasma samples

\begin{tabular}{llllll}
\hline & \multicolumn{2}{l}{ Cilnidipine concentration in human plasma } & \multicolumn{2}{l}{ Nebivolol concentration in human plasma } \\
\cline { 2 - 6 } & $\mathbf{1 6 0 0} \mathbf{n g} / \mathbf{m l}$ & $\mathbf{1 0 0 0} \mathbf{n g} / \mathbf{m l}$ & $\mathbf{6 0 0 n g} / \mathbf{m l}$ & \multicolumn{1}{l}{$\mathbf{1 6 0 n g} / \mathbf{m l}$} & $\mathbf{1 0 0 n g} / \mathbf{m l}$ \\
\hline Mean* & 16.1653 & 9.9265 & 0.6292 & 1.6980 & 1.0703 \\
$\pm \mathrm{SD}$ & 1.11470 & 0.61472 & 0.03286 & 0.13672 & 0.09527 \\
Precisions as CV\% & 6.90 & 6.19 & 5.22 & 8.05 & 0.0588 \\
Accuracy\% & 101.03 & 99.27 & 104.87 & 106.13 & 7.90 \\
\hline
\end{tabular}

*3 determinations 


\section{Inter-day accuracy and precision}

Inter-day accuracy of the method for cilnidipine and nebivolol were ranged from $97.72 \%$ to $102.93 \%$ and $97.87 \%$ to $105.41 \%$ respectively.
While the inter-day precision ranged from $5.77 \%$ to $7.74 \%$ at the concentrations of 600,1000 and $1600 \mathrm{ng} / \mathrm{ml}$ for cilinidipine and $7.41 \%$ to $7.88 \%$ at the concentration of $60,100,160 \mathrm{ng} / \mathrm{ml}$ for nebivolol. The results were presented in (table 2).

Table 2: It shows inter-day precision and accuracy for cilnidipine and nebivolol in spiked human plasma samples

\begin{tabular}{|c|c|c|c|c|c|c|}
\hline & \multicolumn{3}{|c|}{ Cilnidipine concentration in human plasma } & \multicolumn{3}{|c|}{ Nebivolol concentration in human plasma } \\
\hline & $1600 \mathrm{ng} / \mathrm{ml}$ & $1000 \mathrm{ng} / \mathrm{ml}$ & $600 \mathrm{ng} / \mathrm{ml}$ & $160 \mathrm{ng} / \mathrm{ml}$ & $100 \mathrm{ng} / \mathrm{ml}$ & 60ng/ml \\
\hline Mean* & 15.6711 & 9.7723 & 0.6176 & 1.6736 & 1.0541 & 0.0587 \\
\hline$\pm \mathrm{SD}$ & 1.21247 & 0.63934 & 0.03561 & 0.13195 & 0.08591 & 0.00435 \\
\hline Precisions as CV\% & 7.74 & 6.54 & 5.77 & 7.88 & 8.15 & 7.41 \\
\hline Accuracy\% & 97.94 & 97.72 & 102.93 & 104.60 & 105.41 & 97.87 \\
\hline
\end{tabular}

*3 determinations

\section{Accuracy and precision for quality control (QC) samples}

Quality control samples were analyzed for cilnidipine and nebivolol at the three levels 600,1000 and $1600 \mathrm{ng} / \mathrm{ml}$ and 60 ,
100 , and $160 \mathrm{ng} / \mathrm{ml}$. The results were shown in (table 3). The accuracy and precision around the mean value did not exceed 15\% of CV. Hence the developed method met the limits of accuracy and precision.

Table 3: It shows accuracy and precision for cilnidipine and nebivolol quality control samples

\begin{tabular}{|c|c|c|c|c|c|c|}
\hline & \multicolumn{3}{|c|}{ Cilnidipine concentration in human plasma } & \multicolumn{3}{|c|}{ Nebivolol concentration in human plasma } \\
\hline & $\begin{array}{l}\text { QC Low } \\
(600 \mathrm{ng} / \mathrm{ml})\end{array}$ & $\begin{array}{l}\text { QC Mid } \\
(1000 \mathrm{ng} / \mathrm{m})\end{array}$ & $\begin{array}{l}\text { QC High } \\
(1600 \mathrm{ng} / \mathrm{m})\end{array}$ & $\begin{array}{l}\text { QC Low } \\
(60 \mathrm{ng} / \mathrm{ml})\end{array}$ & $\begin{array}{l}\text { QC Mid } \\
(100 \mathrm{ng} / \mathrm{m})\end{array}$ & $\begin{array}{l}\text { QC High } \\
(160 \mathrm{ng} / \mathrm{ml})\end{array}$ \\
\hline Mean* & 164552 & 1252583 & 1958595 & 12513 & 202344 & 327466 \\
\hline$\pm \mathrm{SD}$ & 1061.40 & 16570.99 & 33214.31 & 70.65 & 1284.56 & 2232.86 \\
\hline Precisions as CV\% & 0.65 & 1.32 & 1.70 & 0.56 & 0.63 & 0.68 \\
\hline Accuracy\% & 73.22 & 67.57 & 76.65 & 61.31 & 76.20 & 77.00 \\
\hline
\end{tabular}

*3determination

\section{Recovery}

The absolute and relative recovery determined for cilnidipine and nebivolol shown to be consistent, precise and reproducible at the three levels 600, 1000 and $1600 \mathrm{ng} / \mathrm{ml}$ and $60,100,160 \mathrm{ng} / \mathrm{ml}$.

The data was depicted in (table 4). While, the absolute recovery of amlodipine (IS) was found to be $69.572 \%$.

Table 4: It shows data for sensitivity of lower limit of quantitation (LLOQ)

\begin{tabular}{llll}
\hline Concentration & Actual concentration (ng/ml) & Accuracy \% & Mean (ng/ml)* \\
\hline Cilndipine 200ng/ml & 0.185 & 100.00 & \\
& 0.210 & & \\
& 0.196 & & \\
& 0.231 & & \\
& 0.188 & & \\
Nebivolol 20ng/ml & 0.190 & & \\
& 0.019 & & \\
& 0.020 & & \\
& 0.021 & & \\
& 0.022 & & \\
\hline
\end{tabular}

*6 determinations

\section{Sensitivity}

The sensitivity of the method was established at $200 \mathrm{ng} / \mathrm{ml}$ (LLOQ) of cilnidipinde with \% CV of 8.79 and $2 \mathrm{ng} / \mathrm{ml}$ (LLOQ) of nebivolol with \% CV of 7.07. The data for LLOQ was presented in table 4 . The chromatogram of an extracted plasma sample spiked with $200 \mathrm{ng} / \mathrm{ml}$ and $20 \mathrm{ng} / \mathrm{ml}$ of cilnidipine and nebivolol were shown in (fig. 6).

\section{Matrix effect}

The assessment of matrix effect constitutes an important and integral part of validation for quantitative methods for supporting pharmacokinetics studies. It was performed by processing plasma samples in triplet $(n=3)$. LQC and HQC working solutions were spiked post extraction in duplicate. The results obtained were well within the acceptable limits, as the \%RSD of the area ratios of post spiked recovery samples at $\mathrm{LQC}$ were 7.31 and at $\mathrm{HQC}$ were 7.50 for cilnidipine and at LQC were 7.78 and at HQC were 11.2 for nebivolol which were within $10 \%$. Hence minor suppression or enhancement of analyte signal due to endogenous matrix interferences did not affect the quantification of analytes and IS peak.

\section{Stability studies}

Stability studies were performed to evaluate the stability of cilnidipine and nebivolol both in aqueous solution and in plasma after exposing to various stress conditions. The stability studies performed include stock solution stability of cilnidipine, nebivolol and amlodipine in 
stock solution, stock dilution stability of cilnidipine and nebivolol in dilutions, bench top stability in plasma, free thaw stability in plasma, long term storage stability in plasma and auto sampler stability of processed samples. All stability evaluations were performed as per international regulatory guidelines.

Cilnidipine, nebivolol and amlodipine stock solutions $(1 \mathrm{mg} / \mathrm{ml})$ remained stable when stored at refrigerator conditions for $7 \mathrm{~d}$ including the storage at room temperature for $8 \mathrm{~h}$. Cilnidipine and nebivolol were stable in plasma samples when stored at room temperature for $18 \mathrm{~h}$. Cilnidipine and nebivolol were found to be stable for 3 freeze and thaw cycles. Cilnidipine and nebivolol were stable and did not show any degradation when stored in the freezer for $85 \mathrm{~d}$. Cilnidipine and nebivolol in the processed samples were stable for $60 \mathrm{~h}$ when stored in the auto sampler at $10^{\circ} \mathrm{C}$

Application of the present validated method of analysis for pharmacokinetic study of cilnidipine and nebivolol in human plasma

\section{Application}

The validated method has been successfully used to quantitate cilnidipine and nebivolol concentrations in rabbits, after administration of a single combination dosage form (Tablet containing $10 \mathrm{mg}$ of cilnidipine and $5 \mathrm{mg}$ of nebivolol as an oral dose). The statistical data evaluated were Cmax (maximum observed drug concentration during the study), AUC0-t (area under the plasma concentration-time curve measured to the last quantifiable concentration, using the trapezoidal rule), AUCO $\infty$ (AUCO-t plus additional area extrapolated to infinity, calculated using the formula AUC0-t+Ct/Kel, where Ct is the last measurable drug con-centration), Tmax (time to observe maximum drug concentration). The mean Cmax data obtained, justified the LOQ levels selected, as they are at least less than five half-lives of the obtained Cmax values. The mean Cmax observed for test and reference of cilnidipine 6.2 and $6.0 \mathrm{ng} / \mathrm{ml}$ and 5.6 and $5.8 \mathrm{ng} / \mathrm{ml}$ for nebivolol (fig. 8 and 9). The corresponding mean Tmax for cilnidipine and nebivolol, for test and reference formulations were $2.0 \mathrm{~h}$. The mean AUC0-t test and reference formulations were for cilnidipine 65.57 and $63.45 \mathrm{ng} \times \mathrm{h} / \mathrm{ml}$ and for nebivolol, 74.59 and $74.78 \mathrm{ng} \mathrm{x} \mathrm{hr} / \mathrm{ml}$, respectively while AUC0-inf were 1740 and $1844 \mathrm{ng} \mathrm{x} \mathrm{hr} / \mathrm{ml}$, respectively. The 90\% confidence intervals of the ratios of means Cmax, AUC0-t and AUC0 $\infty$ all fell within the acceptance range of 0.8-1.25, demonstrating the bioequivalence of the two formulations of cilnidipine and nebivolol.

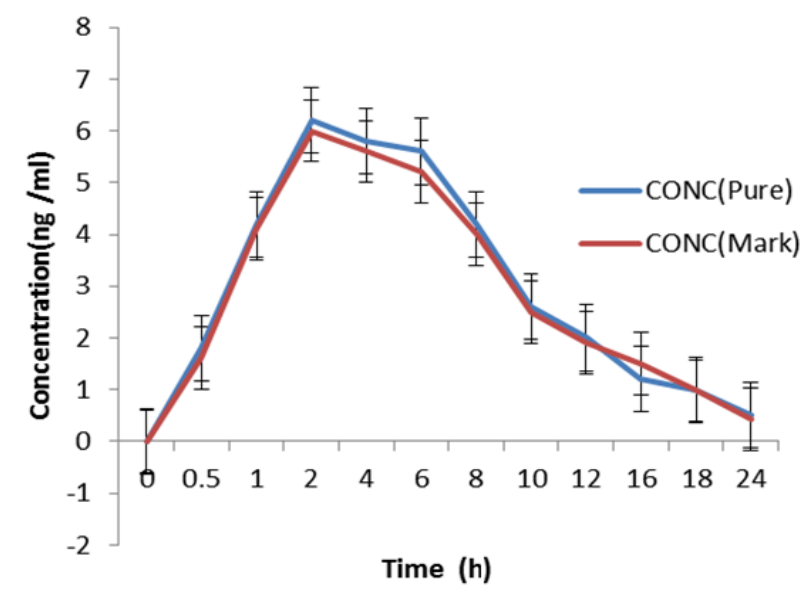

Fig. 8: It shows mean plasma concentrations (mean \pm SD) of cilnidipine versus time profile obtained after a single dose of $L N$ BETA $10 \mathrm{mg}+5 \mathrm{mg}$ tablet administered to 06 healthy male rabbits

\section{CONCLUSION}

Although, many other researchers have provided breakthrough methods for quantification of cilnidipine and nebivolol individually, as can be seen from the references listed. We provide simple, specific, sensitive and rapid method for the simultaneous estimation of cilnidipine and nebivolol from rabbit plasma. The method provided excellent selectivity and linearity with a limit of quantification of $200 \mathrm{ng} / \mathrm{ml}$ and $20 \mathrm{ug} / \mathrm{ml}$ respectively. It has been successfully applied to pharmacokinetic study.

The present study introduced the pharmacokinetic characteristics of cilnidipine and nebivolol tablets administered to rabbit. Besides, the current investigation provides a specific, sensitive, precise, accurate and rapid assay for cilnidipine and nebivolol in human plasma. From the results we conclude that the developed method can be applied in bioequivalence, pharmacokinetic and bioavailability studies of cilnidipine and nebivolol tablets with desired accuracy and precision.

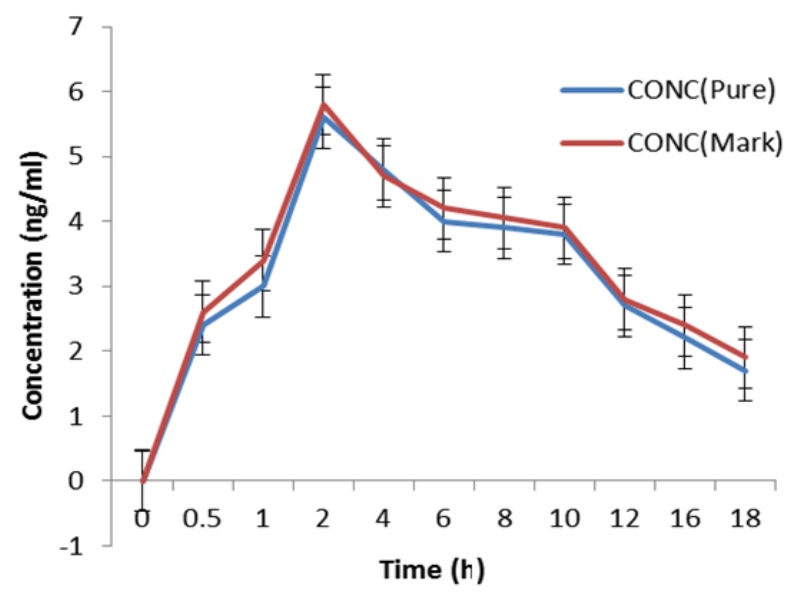

Fig. 9: It shows mean plasma concentrations (mean \pm SD) of nebivolol versus time profile obtained after a single dose of $\mathrm{LN}$ BETA $10 \mathrm{mg}+5 \mathrm{mg}$ tablet administered to 6 healthy male rabbits

\section{ACKNOWLEDGMENT}

The author would like to appreciate the clinical staff and the analytical staff for their kind help and expertise in conducting this study. Beside, sincere thanks to Krishna teja pharmacy college, Tirupati.

\section{AUTHOR CONTRIBUTION}

All the author were equally contributed in the research and preparation of manuscript.

\section{CONFLICT OF INTERESTS}

Declared none

\section{REFERENCES}

1. Sharma T, Rajesh P. Development and validation of UV spectrophotometric method for determination of nebivolol hydrochloride following ICH guidlines and study of its degradation profile. Asian J Pharm Clin Res 2012;5:69-72.

2. Kokilambiga KS, Lakshmi KS. Analytical methodologies for determination of cilnidipine an overview. Int J Pharm Pharm Sci 2014;6:36-8.

3. Reema H Rupareliya, Hitendra S Joshi. Stability indicating simultaneous validation of telmisartan and cilnidipine with forced degradation behavior study by RP-HPLC in tablet dosage form. ISRN Chromatography 2013;6:1-7.

4. Shah DM, Doshi DB. Development and validation of HPTLC method for simultaneous estimation of nebivolol hydrochloride and cilnidipine in combined pharmaceutical tablet dosage form. Int J Pharma Res Rev 2016;5:1-7.

5. Jaldeepsinh V, Rathod, Dilip G, Maheshwari. Development and validation of second order derivative spectrophotometric method for simultaneous estimation of cilnidipine and valsartan in synthetic mixture. Am J PharmTech Res 2015;5:314-24. 
6. Lakshmi Aswini G, Dachinamoorthy D, Seshagiri Rao J. Stability indicating RP-HPLC-PDA method for simultaneous estimation of olmesartan, cilnidipine and chlorthalidone with forced degradation behavior study in bulk and in its tablet dosage form. Am J PharmTech Res 2015;5:379-92.

7. Mohammad Yunoos, Gowri Sankar D. Validated stability indicating RP-HPLC method for simultaneous quantitative estimation of hydrochlorothiazide and nebivolol hydrochloride in bulk and combined tablet dosage form. Am J PharmTech Res 2015;5:507-19.

8. Manzoor A, Rashmi DR, Satishkumar Shetty A, Anil Kumar SM, Ravi MC, Kuppast IJ. RP-HPLC method development and validation for simultaneous estimation of cilnidipine and olmesartan medoxomil in combined tablet dosage form. World J Pharm Pharm Sci 2015;4:785-95.

9. Zeel T Doshi, Jignesh S, Shah, Dilip G, Maheshwari. A review on analytical method for determination of calcium channel blocker in different dosage forms. J Global Trends Pharm Sci 2015;6:2829-39.

10. Ravisankar P, Devala Rao G. Rapid separation and quantification of certain anti-hypertensive agents in their dosage forms by reversed phase-high performance liquid chromatography. Indo Am J Pharm Res 2015;5:2335-58.

11. Prasad S, Virkar, Satish G, Pingale, Kiran V, Mangaonkar. Development and validation of a high performance liquid chromatography method for determination of telmisartan in rabbit plasma and its application to a pharmacokinetic study. Anal Bioanal Techniques 2012;3:1-5.

12. Jaafar JI, Tamimi A. Development and validation of HPLC/UV method for determination of meloxicam in human plasma and application in pharmacokinetic studies. Int J Pharm Pharm Sci 2014;7:370-8.

13. Pharne AB, Santhakumari BA, Ghemud S, Jain HK, Kulkarni MJ. Bioanalytical method development and validation of vildagliptin a novel dipeptidyl peptidase IV inhibitor by RPHPLC method. Int J Pharm Pharm Sci 2012;4:119-23.

14. Swathimutyam P, Prabhakar B. Bio analytical method development and validation of temozolomide in rat plasma using RP-HPLC method. Int J Pharma Sci Res 2016;7:1298-301.

15. Hendriks G. Review theoretical models in LC based bioanalytical method development. J Pharm Biomed Anal 2009;46:1-10.

16. International Conference on Harmonization (ICH), Validation of analytical methods definitions and terminology. ICH Q2 A; 1994.

17. International Conference on Harmonization (ICH), Validation of analytical methods. Methodology, ICH Q2B; 1996.

\section{How to cite this article}

- $\quad$ Aruna G, Bharathi K, Kvsrg Prasad. Development and validation of bioanalytical HPLC method for simultaneous estimation of cilnidipine and nebivolol in human plasma. Int J Pharm Pharm Sci 2017;9(10):253-259. 